\title{
Adherence to antiretroviral therapy during pregnancy and the first year postpartum among HIV-positive women in Ukraine
}

Heather Bailey ${ }^{1 *}$, Claire Thorne ${ }^{1}$, Ruslan Malyuta ${ }^{2}$, Claire L Townsend ${ }^{1}$, Igor Semenenko ${ }^{2}$, Mario Cortina-Borja', for the Ukraine European Collaborative Study Group in EuroCoord

\begin{abstract}
Background: Poor adherence to antiretroviral therapy (ART) is associated with HIV disease progression and, during pregnancy, increased mother-to-child transmission risk. In Ukraine, access to combination ART is expanding but data on adherence are scarce.

Methods: Cross-sectional surveys of HIV-positive women were conducted i) at delivery (on antenatal ART adherence) and ii) during the first year postpartum (on ART adherence in the preceding four weeks). Factors associated with a score $\leq 11$ on the self-report Case Adherence Support Evaluation (CASE) index or $\geq 1$ self-reported missed dose were assessed using Fisher's exact test.
\end{abstract}

Results: Of 185 antenatal participants and 102 postnatal participants, median ages were 27.5 and 29.5 years respectively: 28\% (50/180) and 27\% (26/98) reported an unplanned pregnancy, and 13\% (24/179) and 17\% (17/98) an illicit drug-use history (excluding marijuana). One quarter (49/180 antenatally, 27/101 postnatally) screened positive for depression. The proportion reporting 'low' ART-related self-efficacy (i.e. unable to do $\geq 1 / 5$ ART-taking activities) was 20\% (28/141) antenatally and 17\% (11/66) postnatally. Antenatally, 14\% (95\% Cl 10-21\%) had a CASE score $\leq 11$ and $35 \%$ (95\% Cl 28-42\%) reported missing $\geq 1$ dose. Factors associated with a CASE score $\leq 11$ were unplanned pregnancy ( $25 \%(12 / 48)$ vs. $11 \%(13 / 120)$ where planned, $p=0.03)$ and living with extended family (23\% (13/57) vs. 10\% (12/125) living with partner/alone, $p=0.04)$. Self-report of $\geq 1$ missed dose antenatally was additionally associated with younger age $(p=0.03)$ and lower self-efficacy (50\% (14/28) reported $\geq 1$ missed dose vs. $28 \%(30 / 108)$ of those with high self-efficacy, $p=0.04$ ). Of 102 postnatal participants, 8\% (95\% Cl 4-15\%) had a CASE score $\leq 11$ and 31\% (95\% Cl 22-41\%) reported $\geq 1$ missed dose. Of 11 women with low self-efficacy, 3 (27\%) had a CASE score $\leq 11$ compared with $3 / 55(5 \%)$ of those with high self-efficacy $(p=0.05)$. Current smokers more commonly reported $\geq 1$ missed dose postnatally (50\% (13/26) vs. $25 \%$ (18/72) of non-smokers, $p=0.03)$.

Conclusions: Our results highlight unmet needs for counselling and support. We identify some groups at risk of poor ART adherence, including women with markers of social vulnerability and those with low ART-related self-efficacy, who may benefit from targeted interventions.

Keywords: HIV, Antiretroviral therapy, Adherence, Self-efficacy, Ukraine, Eastern Europe, Women, Pregnancy, Prevention of mother-to-child transmission

\footnotetext{
* Correspondence: heather.bailey@ucl.ac.uk

${ }^{1}$ Population Policy and Practice Programme, UCL Institute of Child Health, University College London, 30 Guilford Street, London WC1N 1EH, UK Full list of author information is available at the end of the article
} 


\section{Background}

Ukraine is a lower middle-income country which, along with Russia, accounts for around 90\% of new HIV infections in Eastern Europe [1] - a region with an injecting drug use (IDU)-driven epidemic which continues to accelerate, in contrast with worldwide trends [2]. Newly diagnosed HIV infections in Ukraine are now equally distributed between women and men with adult HIV prevalence $>1 \%$ overall [3]. In 2011, AIDS-related morbidity and mortality rates were 8.2 and 20.1 per 100,000 population respectively and $44 \%$ of AIDS diagnoses were in individuals not previously aware of their HIV infection [3].

Scale-up of antiretroviral therapy (ART) has been slow, but access to combination ART (cART) for HIV-positive pregnant women in Ukraine expanded following the shift in 2007 from a World Health Organisation (WHO) Option A policy (i.e. cART for women with treatment indications and zidovudine monotherapy (ZDVm) for those who require ART for prevention of MTCT (PMTCT) only) to an Option B policy (i.e. cART for all HIV-positive pregnant women) [4]. Antenatal cART coverage reached $60 \%$ in 2010 and $80 \%$ in 2011 [3,5]. Access to cART among the general population is also improving: of ART-eligible individuals in HIV care in 2011, around 70\% were receiving cART [3], up from $48 \%$ in 2009 [6]. The success of expanded cART coverage in improving health outcomes depends on adherence to treatment, low levels of which are associated with HIV disease progression, mortality and development of de novo resistance to antiretroviral drugs [7-9]. During pregnancy, a compromised virological response to cART also increases risk of mother-to-child transmission (MTCT) of HIV [10,11], including of drug resistant virus [12]. Lower levels of adherence to ART during pregnancy have elsewhere been associated with use of illicit drugs, alcohol and tobacco [13-15], although not consistently [16,17], possibly because of the importance of context-specific factors, particularly availability of harm reduction services [18]. Access to opioid substitution therapy in Ukraine is poor, with only 6,632 of an estimated 250,000 people injecting opiates receiving methadone or buprenorphine by the end of 2011 [3].

Information on adherence to ART during pregnancy and postnatally is essential for the strengthening of PMTCT and treatment programmes in Ukraine, where second-line ART options are currently lacking [19]. To our knowledge, there are no published data on ART adherence in Ukraine and little information available on adherence more widely in Eastern Europe, particularly among childbearing women, who may have different levels of and motivations for adherence than the general population [20]. In other settings, the immediate postpartum period has been found to be a time of high risk for poor ART adherence [13,14,21-23]. The aim of this study was to investigate levels and determinants of selfreported ART adherence during pregnancy and the first year postpartum among women with HIV in Ukraine.

\section{Methods}

The European Collaborative Study (ECS) is an observational cohort study of HIV-infected pregnant women and their infants, active in Ukraine since 2000. At the time of this study, the ECS was enrolling around $30 \%$ of HIV-positive pregnant women in Ukraine at seven regional HIV/AIDS centres [5]. Linked anonymous data are collected on maternal and delivery characteristics and infant infection status, following informed consent.

For this investigation of ART adherence during pregnancy and postnatally, two cross-sectional surveys were conducted. The antenatal survey took place at three maternity hospitals among women who had taken $\geq 4$ weeks of antenatal ART, who were invited to participate during their postnatal hospital stay (typically of $\geq 3$ days). The postnatal survey took place at six HIV/AIDS centres among women attending between 1 and 12 months postpartum for routine infant follow-up and ongoing HIV care, who were currently on ART. See the Acknowledgements section for a full list of participating sites and information on ethics and institutional approvals. Survey participation was open to all women meeting the eligibility criteria, regardless of whether they were enrolled in the ECS. Participants gave informed consent and completed a paper-based questionnaire. Unique study identifiers allowed clinicians to refer women for additional support where necessary, while ensuring participant anonymity to researchers.

The survey period was from July to December 2011, with extension to April 2012 for sites with operational problems (e.g. periods of ward closure). We constructed indirect measures of survey participation for the main six-month study period. For the antenatal survey, the number of surveys returned was calculated as a proportion of the 240-300 deliveries to HIV-positive women at participating hospitals over the main six-month survey period (of whom 90\% were estimated to be eligible [5]). For the postnatal survey, data from a postnatal cohort nested within the ECS on number of women attending HIV care postnatally were used to calculate participation rates. There were fewer postnatal than antenatal participants because only around a fifth of women continue ART after delivery in Ukraine, with many of the remainder not yet meeting eligibility criteria for treatment [24]. Survey responses were matched to ECS data using maternal date of birth, date of delivery, infant sex and centre, and characteristics of survey participants compared with those of women who did not participate to explore the survey population's representativeness. Associations between adherence and clinical characteristics were explored in the subgroup with ECS data available. 
Data collected in the adherence surveys included ART adherence, socio-demographic characteristics, health behaviours, disclosure of HIV status, experience of ART side effects, reasons for missed doses of ART (from the AIDS Clinical Trials Group adherence tool [25]), symptoms of depression and ART-related self-efficacy. Women's perceptions of the risks and benefits of ART for PMTCT were explored using questions from the NIAID Adult AIDS Clinical Trials Group supplemental antepartum adherence questionnaire [26]. Postnatally, women were asked if and how their adherence had changed following delivery (question adapted from Mellins et al. [13]).

\section{Definitions}

Self-reported adherence to ART was measured using the Case Adherence Support Evaluation (CASE) index tool. Answers to three questions (on difficulty taking medications on time, frequency of missed doses, and timing of last missed dose) give a score of between 3 and 16, with higher scores indicating better adherence [27]. Previous studies validating this tool against viral load have determined best score cut-offs for defining 'poor' ART adherence to be $\leq 10$ [27], $\leq 11$ [28] and $\leq 12$ [29]; in this study, a score of $\leq 11$ was chosen as it showed the greatest association with viral load measures in validation analyses (data not shown). Responses were also categorised according to whether any missed doses were reported (one potentially valid approach [30]); ' $\geq 1$ missed dose' referred to the whole of pregnancy in the antenatal survey, and the preceding four weeks in the postnatal survey.

Symptoms of depression over the last month were measured using Patient Health Questionnaire-2 Screening Questions from the Primary Care Evaluation of Mental Disorders [31], with a positive depression screening test result defined as self-reported anhedonia and low mood, or one of these and a positive response to an enquiry about the need for help [32].

ART-related self-efficacy was measured using five questions adapted from the HIV Treatment Adherence SelfEfficacy Scale [33]. Participants indicated their level of confidence from 'could not do' [0 points], 'fairly confident I could do' [ 1 point] and 'confident I could do' [ 2 points]. Women answering all five questions and scoring $<5$ were defined as having low self-efficacy. Two questions about help-seeking self-efficacy were also included.

\section{Data analysis}

Univariable comparisons were assessed with the $\chi^{2}$ test and the Fisher's exact test for categorical variables and the Wilcoxon Mann-Whitney test for medians; unless otherwise stated, $p$-values were obtained using two-sided Fisher's exact tests. Multivariable analyses were not conducted, because the number of participants and intercorrelation of many factors associated with poor adherence meant that statistical power was insufficient to adjust for confounding. The aim of this work was to characterise women likely to benefit most from targeted adherence support, rather than to establish the relative importance of independent factors. Data were managed using REDCap electronic data capture tools hosted at University College London Institute of Child Health [34]. Statistical analyses were performed using STATA version 11.0 (StataCorp, LP, College Station, Texas, USA).

\section{Results}

A total of 287 women participated in the surveys (185 in the antenatal and 102 in the postnatal survey); seven women completed both surveys. Participant characteristics are shown in Table 1 . Of the 185 antenatal study participants, 106 took part during the main six-month survey period, giving a participation rate among eligible women of 39-49\% (based on 240-300 HIV-positive women delivering at participating hospitals in this period, of whom an estimated $90 \%$ - i.e. $216-270$ - had taken $\geq 4$ weeks of antenatal ART and thus met eligibility criteria). Of the total 102 postnatal participants, 63 took part during the main six-month survey period at five HIV/AIDS centres with denominator data available; these 63 women were estimated to represent $75 \%(63 / 84)$ of women on ART at their first visit to the HIV/AIDS centre following delivery.

Postnatal participants completed the survey a median of 5.3 months after delivery, and were a median of two years older than antenatal participants. Around three-quarters in each group were living with a husband or partner (Table 1). In the antenatal survey, 15\% $(n=20)$ of the 132 women living with a husband or partner were also living with other adult family members, while in the postnatal survey this proportion was $14 \%$ (11/80). Overall, women living with their family were younger (median age 26.6 years vs. 28.6 years for women living only with a partner or alone in the antenatal survey, Wilcoxon-MannWhitney test $p=0.02$ ) and more likely to have had an unplanned pregnancy $(36 \%(21 / 58)$ vs. $23 \%(27 / 120)$ of those living only with a partner or alone, $\left.\mathrm{x}^{2}=3.73 p=0.05\right)$. This was also the case in the postnatal survey group, although comparisons were not statistically significant; women living with their family had a median age of 27.9 years vs 29.9 years for the rest of the group (Wilcoxon-MannWhitney $p=0.27)$, and $36 \%(8 / 22)$ had an unplanned pregnancy vs. $24 \%(18 / 75)$ of those living with a partner only or alone $\left(\chi^{2}=1.33 p=0.25\right)$.

ECS data were available for 97 (52\%) of antenatal and 44 (43\%) of postnatal participants at the time of analysis; clinical and treatment data on this sub-group are shown in Table 2, along with ECS data on women who did not participate in the adherence surveys. In the antenatal survey, $12 \%$ of women were taking mono/dual therapy (Table 2). Of those on cART and reporting their regimen 
Table 1 Characteristics of survey participants

\begin{tabular}{|c|c|c|}
\hline & $\begin{array}{l}\text { Antenatal survey } \\
(n=185)\end{array}$ & $\begin{array}{l}\text { Postnatal survey } \\
(n=102)\end{array}$ \\
\hline $\begin{array}{l}\text { Median age at } \\
\text { participation (IQR) }\end{array}$ & $\begin{array}{l}27.5 \text { years } \\
(25.0,30.9)\end{array}$ & $\begin{array}{l}29.5 \text { years } \\
(25.9,33.5)\end{array}$ \\
\hline $\begin{array}{l}\text { Median time since } \\
\text { delivery (IQR) }\end{array}$ & 1 day $(1,2)$ & 5.3 months $(2.4,7.8)$ \\
\hline \multicolumn{3}{|l|}{ Marital status } \\
\hline Married & $100(54 \%)$ & $55(54 \%)$ \\
\hline Cohabiting & $51(28 \%)$ & $23(23 \%)$ \\
\hline Single & $34(18 \%)$ & $24(24 \%)$ \\
\hline Pregnancy unplanned & $50(28 \%)$ & $26(27 \%)$ \\
\hline \multicolumn{3}{|l|}{ Living with $^{\dagger}$} \\
\hline Husband/partner & $132(72 \%)$ & $80(79 \%)$ \\
\hline $\begin{array}{l}\text { Extended family } \\
\text { (including parents) }\end{array}$ & $60(33 \%)$ & $23(23 \%)$ \\
\hline $\begin{array}{l}\text { Living as only } \\
\text { adult in household }\end{array}$ & $12(7 \%)$ & $13(13 \%)$ \\
\hline \multicolumn{3}{|l|}{ Disclosure of HIV status ${ }^{\dagger}$} \\
\hline To husband/partner & $135(74 \%)$ & $80(79 \%)$ \\
\hline To family or friend(s) & 108 (59\%) & $55(54 \%)$ \\
\hline To no one at all & $16(9 \%)$ & $7(7 \%)$ \\
\hline \multicolumn{3}{|l|}{$\begin{array}{l}\text { Do you have someone } \\
\text { you can rely on to help } \\
\text { you care for your baby? }\end{array}$} \\
\hline Yes & 164 (91\%) & $89(88 \%)$ \\
\hline No & $17(9 \%)$ & $12(12 \%)$ \\
\hline \multicolumn{3}{|l|}{$\begin{array}{l}\text { Smoking, alcohol } \\
\text { and drug use }\end{array}$} \\
\hline Current smoker & $49(27 \%)$ & $28(28 \%)$ \\
\hline Current alcohol use & $168(9 \%)$ & $8(8 \%)$ \\
\hline Ever used marijuana & $25(14 \%)$ & $15(15 \%)$ \\
\hline $\begin{array}{l}\text { Ever used illicit drugs } \\
\text { other than marijuana }\end{array}$ & $24(13 \%)$ & $17(17 \%)$ \\
\hline \multicolumn{3}{|l|}{$\begin{array}{l}\text { Severity of ART } \\
\text { side effects }\end{array}$} \\
\hline $\begin{array}{l}\text { Not bothered by side } \\
\text { effects or only slightly }\end{array}$ & $132(75 \%)$ & $76(76 \%)$ \\
\hline $\begin{array}{l}\text { Somewhat or terribly } \\
\text { bothered by side effects }\end{array}$ & $44(25 \%)$ & $24(24 \%)$ \\
\hline \multicolumn{3}{|l|}{ Use of support services ${ }^{\dagger}$} \\
\hline Currently using support group & $10(5 \%)$ & $21(21 \%)$ \\
\hline $\begin{array}{l}\text { Currently using peer } \\
\text { counselling }\end{array}$ & $10(5 \%)$ & $27(26 \%)$ \\
\hline Currently using social services & $40(22 \%)$ & $28(27 \%)$ \\
\hline $\begin{array}{l}\text { Currently using adherence } \\
\text { programme }\end{array}$ & $4(2 \%)$ & $39(38 \%)$ \\
\hline
\end{tabular}

${ }^{\dagger}$ Groups not mutually exclusive.

in full, 91\% (86/94) in the antenatal survey and 80\% (47/ 59) postnatally were taking a ritonavir-boosted lopinavirbased regimen. Most women (antenatal: 72\% (102/142), postnatal: 56\% (40/72)) were taking six antiretroviral pills a day. Postnatal participants were more likely to have WHO stage 3-4 disease (39\% (16/41) vs. $22 \%(19 / 86)$ of antenatal participants, $\left.x^{2}=3.99 p=0.05\right)$ and had been taking ART for longer (Table 2, Wilcoxon Mann-Whitney test $p<0.01$ ), reflecting their indications for treatment rather than for PMTCT only. Of note, adherence study participants had higher levels of education compared with women enrolled in the ECS only (92\% (35/38) remained in full-time education until $\geq 17$ years of age vs. $74 \%$ (595/ 799) of women in the ECS only, Fisher's exact test $p=$ $0.01)$.

A quarter of women screened positive for depression (49/180 antenatally and 27/101 postnatally). With regards ART-related self-efficacy, the area in which women most commonly lacked confidence was in their ability to keep taking medication if experiencing side effects (Table 3). Most reported being able to share concerns with their clinician, but fewer were able to ask someone for support with taking their medication (Table 3). Although most antenatal survey participants were completely $(44 \%, 80 /$ $180)$ or fairly $(51 \%, 91 / 180)$ sure that antenatal ART was effective for PMTCT, 82\% (149/181) were at least a little worried that it might harm their baby. Women who were completely sure of the effectiveness of ART were less likely to be worried about harm $(74 \%(59 / 80)$ vs. $88 \%(80 / 91)$ of those who were only fairly sure of its effectiveness, $x^{2}=$ $5.61 p=0.02$ ).

\section{Prevalence of poor adherence and reasons for missed doses}

Median CASE scores were 15 (of a possible 16) in both the antenatal survey $(n=173)$ and the postnatal survey $(n=99)$ (antenatal: IQR 13, 16, range 6, 16; postnatal: IQR 14, 16, range 7, 16). The proportion with a CASE score $\leq 11$ (defined as 'poor' adherence) was 14\% (25/ $173,95 \%$ CI 10-21\%) in the antenatal survey and $8 \%(8 /$ 99, 95\% CI 4-15\%) in the postnatal survey, while 35\% (61/176, 95\% CI $28-42 \%)$ and 31\% (31/100, 95\% CI $22-$ $41 \%)$ reported having missed $\geq 1$ dose during pregnancy and in the last four weeks respectively. Antenatally, the most common reasons for missing a dose were being away from home $(8 \%, 14 / 185)$, forgetting $(5 \%, 10 / 185)$ and feeling sick or ill $(5 \%, 10 / 185)$, while postnatally these were forgetting $(15 \%, 15 / 102)$, sleeping through the dose $(9 \%, 9 / 102)$ and being away from home $(8 \%, 8 /$ $102)$. In the postnatal survey, $13 \%$ (12/93) reported having missed fewer doses during pregnancy than postnatally, 2\% (2/93) having missed fewer doses postnatally than when pregnant, $6 \%$ (6/93) having unchanged adherence, and 78\% (73/93) having missed no doses in either time period. Of the 12 women who reported adhering to ART better during pregnancy than postnatally, 11 cited concerns about MTCT as a reason for this. 
Table 2 Clinical characteristics and ART use among adherence study participants with matched ECS data available, and their representativeness with respect to women enrolled in the ECS

Adherence study

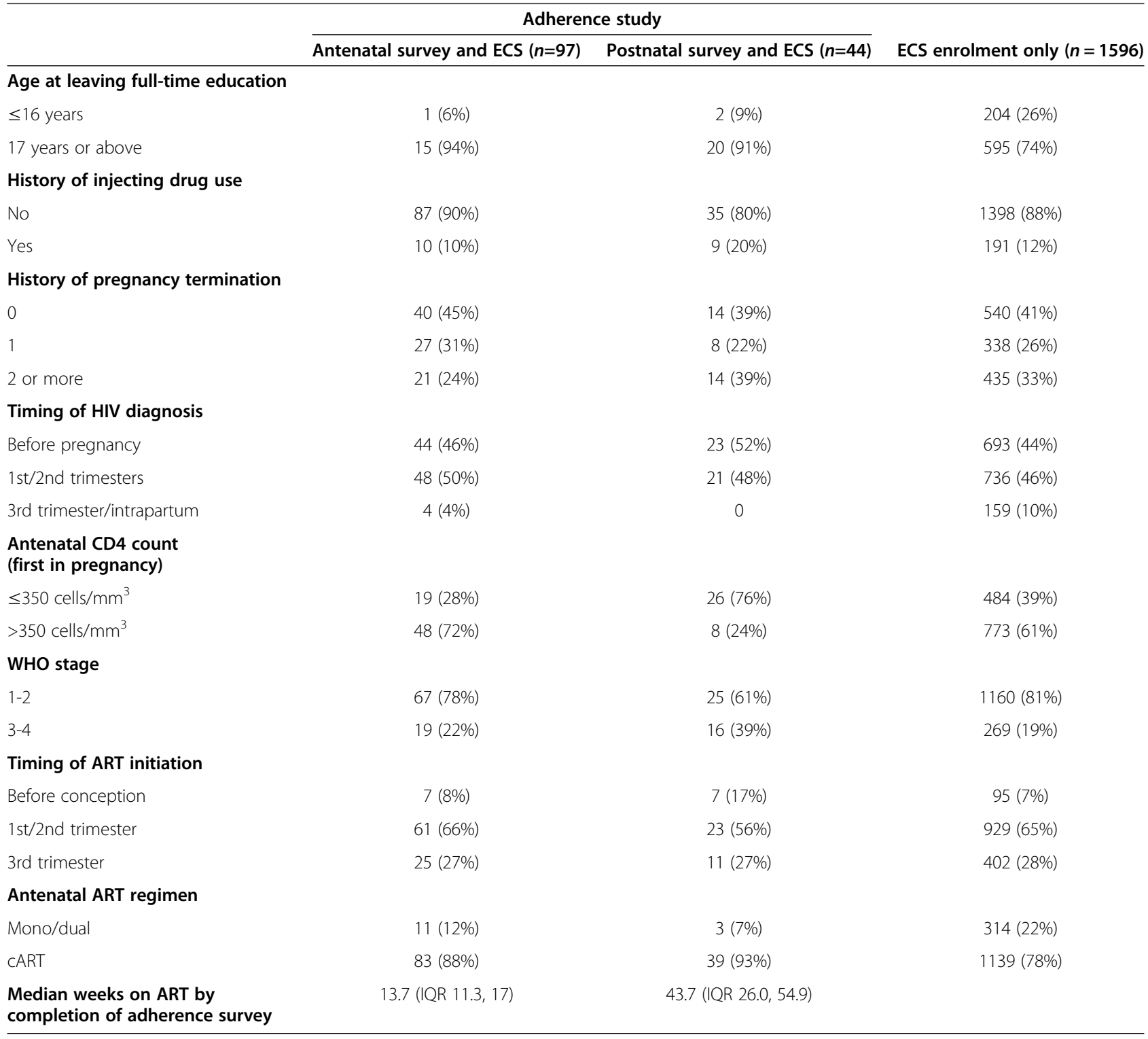

\section{Factors associated with poor adherence}

\section{during pregnancy}

Table 4 shows factors associated with a CASE score $\leq 11$ and with reporting $\geq 1$ missed dose during pregnancy. Women living with their extended family (a factor correlated with youth and unplanned pregnancy) were more likely to report poor adherence, particularly if they had not disclosed their HIV status to a family member $(40 \%$ $(8 / 20)$ of whom had a CASE score $\leq 11$ vs. $14 \%(5 / 37)$ living with family who had disclosed their status to a family member, $p=0.04$ ). Overall however, disclosure of HIV status to at least one other person (reported by $91 \%$ (167/183) of women) was not associated with adherence (Table 4). Among married/cohabiting women, 83\%
(124/150) had disclosed their HIV status to their partner, of whom $32 \%(37 / 116)$ reported missing $\geq 1$ dose during pregnancy compared with $42 \%(11 / 26)$ who had not disclosed their HIV status to their partner $(p=0.36)$.

There was some evidence of an association between current smoking and reporting of $\geq 1$ missed dose during pregnancy $(p=0.07)$, but not between history of illicit drug use and adherence (Table 4). A positive depression screening test result was weakly associated with increased likelihood of reporting $\geq 1$ missed dose (Table 4). Adherence did not differ by whether ART was perceived as safe ( $p=$ 1.00 for $\geq 1$ missed dose), but there was some evidence that adherence was poorer among the small group of women unsure of the effectiveness of ART for PMTCT 
Table 3 Measures of self-efficacy

\begin{tabular}{|c|c|c|c|c|c|c|}
\hline & \multicolumn{3}{|c|}{ Antenatal survey } & \multicolumn{3}{|c|}{ Postnatal survey } \\
\hline & $\begin{array}{l}\text { Confident } \\
\text { could do }\end{array}$ & $\begin{array}{l}\text { Fairly confident } \\
\text { could do }\end{array}$ & $\begin{array}{l}\text { Could } \\
\text { not do }\end{array}$ & $\begin{array}{l}\text { Confident } \\
\text { could do }\end{array}$ & $\begin{array}{l}\text { Fairly confident } \\
\text { could do }\end{array}$ & $\begin{array}{l}\text { Could } \\
\text { not do }\end{array}$ \\
\hline \multicolumn{7}{|l|}{ ART-related self-efficacy } \\
\hline 1. Keep taking ART if side effects interfere & $40 \%(68 / 171)$ & $46 \%(78 / 171)$ & $15 \%(25 / 171)$ & $29 \%(26 / 89)$ & $51 \%(45 / 89)$ & $20 \%(18 / 89)$ \\
\hline $\begin{array}{l}\text { 2. Keep taking ART in front of people } \\
\text { unaware of your HIV status }\end{array}$ & $43 \%(75 / 175)$ & $46 \%(81 / 175)$ & $11 \%(19 / 175)$ & $31 \%(27 / 88)$ & $59 \%(52 / 88)$ & $10 \%(9 / 88)$ \\
\hline 3. Keep taking ART if daily routine disrupted & $45 \%(78 / 173)$ & $47 \%(81 / 173)$ & $8 \%(14 / 173)$ & $41 \%(35 / 86)$ & $57 \%(49 / 86)$ & $2 \%(2 / 86)$ \\
\hline 4. Keep taking ART if not feeling well & $43 \%(77 / 178)$ & $47 \%(83 / 178)$ & $10 \%(18 / 178)$ & $24 \%(20 / 85)$ & $62 \%(53 / 85)$ & $14 \%(12 / 85)$ \\
\hline $\begin{array}{l}\text { 5. Keep attending appointments if } \\
\text { they interfere with daily activities }\end{array}$ & $36 \%(54 / 148)$ & $55 \%(82 / 148)$ & $8 \%(12 / 148)$ & $45 \%(32 / 71)$ & $52 \%(37 / 71)$ & $3 \%(2 / 71)$ \\
\hline $\begin{array}{l}\text { Proportion reporting that they could } \\
\text { not do } \geq 1 \text { of } 5 \text { ART-related items }\end{array}$ & $20 \%(28 / 141)$ & & & $17 \%(11 / 66)$ & & \\
\hline \multicolumn{7}{|l|}{ Help-seeking self-efficacy } \\
\hline $\begin{array}{l}\text { 1. Ask clinician for more information } \\
\text { or tell them about concerns or worries }\end{array}$ & $37 \%(61 / 167)$ & $56 \%(94 / 167)$ & $7 \%(12 / 167)$ & $48 \%(41 / 86)$ & $49 \%(42 / 86)$ & $3 \%(3 / 86)$ \\
\hline $\begin{array}{l}\text { 2. Ask someone for support with } \\
\text { taking medication if needed }\end{array}$ & $33 \%(54 / 165)$ & $47 \%(78 / 165)$ & $20 \%(33 / 165)$ & $30 \%(26 / 86)$ & $43 \%(37 / 86)$ & $27 \%(23 / 86)$ \\
\hline
\end{tabular}

(Table 4). Women who received ZDVm were more likely to report $\geq 1$ missed dose compared with those on cART (Table $4, p=0.02$ ), while those who were confident to ask their doctor for support had higher CASE scores than those who reported that they could not do this (Table 4). However, there was no difference in adherence by severity of HIV disease (13\% (8/64) and 11\% (2/17) of women with WHO stage 1-2 and 3-4 disease had a CASE score of $\leq 11$ respectively, $p=1.00$; subgroup with ECS data).

\section{Factors associated with poor adherence in the year following delivery}

Factors associated with a CASE score $\leq 11$ or with reporting $\geq 1$ missed dose in the last four weeks in the postnatal survey are shown in Table 5 . Current smokers were more likely to report $\geq 1$ missed dose, as were women with a history of illicit drug use and those not using a treatment adherence programme $(p=0.08$ for latter two factors, Table 5). Women who had not disclosed their HIV status to anyone were more likely to report having missed $\geq 1$ dose, and there was some indication of lower ART adherence among unmarried and single women (vs. married women) and those not living with a partner (Table 5), although small numbers limited statistical power. Women with low self-efficacy were more likely to have a CASE score $\leq 11$, but there was no association between adherence and depression screening test result postnatally and severity of self-reported ART side effects was also not associated with adherence (Table 5). Of the subgroup with ECS data available, 36\% (9/25) of women with WHO stage 1-2 disease reported having missed a dose in the last four weeks vs. $13 \%(2 / 16)$ of those with WHO stage 3-4 disease $(p=0.15)$.

\section{Discussion}

In this cross-sectional study of ART adherence in childbearing women in Ukraine, poor adherence (defined as a score of $\leq 11$ on the CASE adherence index measure) was reported by $14 \%$ (95\% CI 10-21\%) of women during pregnancy and $8 \%$ (95\% CI 4-15\%) of women in their first year postpartum. A third of women in the antenatal survey reported missing at least one dose during pregnancy, and a similar proportion postnatally reported missing at least one dose in the preceding four weeks. Cross-study comparisons of ART adherence are problematic due to the range of assessment methods and outcomes used; a recent meta-analysis estimated that $72 \%$ of women took $>80 \%$ of ART doses during pregnancy [20], but self-reported measures (as used in this study) are generally inflated compared with more objective measures [35-37]. Despite fairly high levels of adherence in our study, most women $(>80 \%)$ were worried about the safety of antenatal ART, a quarter screened positive for depression, and one in four reported being somewhat or terribly bothered by ART side effects. Unmet need for support may impact on the sustainability of ART adherence beyond pregnancy and the first year following delivery.

Levels of adherence reported during and after pregnancy were similar, but there were important differences between the survey groups, particularly with respect to HIV disease stage, reflecting the fact that a large proportion of HIVpositive women stop ART after delivery in this setting, as they lack indications for treatment. Risk of disengagement from HIV care is high in the postnatal period, and women with risk factors for poor adherence may have been under-represented in our postnatal survey if they were 
Table 4 Factors associated with poor ART adherence during pregnancy

\begin{tabular}{|c|c|c|c|c|}
\hline & $\begin{array}{l}\text { CASE score } \leq 11 \\
\text { points }(25 / 173)\end{array}$ & Fisher's exact test & $\begin{array}{l}\geq 1 \text { missed } \\
\text { dose }(61 / 176)\end{array}$ & Fisher's exact test \\
\hline \multicolumn{5}{|l|}{ Age } \\
\hline$<25$ years & $26 \%(11 / 42)$ & $p=0.13$ & $52 \%(23 / 44)$ & $p=0.03$ \\
\hline $25-27$ years & $10 \%(5 / 48)$ & & $23 \%(11 / 48)$ & \\
\hline 28-30 years & $12 \%(5 / 41)$ & & $29 \%(12 / 41)$ & \\
\hline$\geq 31$ years & $10 \%(4 / 42)$ & & $35 \%(15 / 43)$ & \\
\hline \multicolumn{5}{|l|}{ Marital status } \\
\hline Married & $14 \%(13 / 93)$ & $p=0.96$ & $34 \%(32 / 95)$ & $p=0.83$ \\
\hline Cohabiting & $15 \%(7 / 48)$ & & $33 \%(16 / 48)$ & \\
\hline Single & $16 \%(5 / 32)$ & & $39 \%(13 / 33)$ & \\
\hline \multicolumn{5}{|l|}{ Pregnancy planned } \\
\hline Yes & $11 \%(13 / 120)$ & $p=0.03$ & $30 \%(36 / 122)$ & $p=0.02$ \\
\hline No & $25 \%(12 / 48)$ & & $49 \%(24 / 49)$ & \\
\hline \multicolumn{5}{|l|}{ Lives with family } \\
\hline No & $10 \%(12 / 115)$ & $p=0.04$ & $29 \%(34 / 117)$ & $p=0.04$ \\
\hline Yes & $23 \%(13 / 57)$ & & $46 \%(26 / 57)$ & \\
\hline \multicolumn{5}{|l|}{ Lives with partner } \\
\hline No & $18 \%(9 / 49)$ & $p=0.47$ & $45 \%(22 / 49)$ & $p=0.08$ \\
\hline Yes & $13 \%(16 / 123)$ & & $30 \%(38 / 125)$ & \\
\hline \multicolumn{5}{|l|}{ Disclosed HIV status to anyone } \\
\hline No & $20 \%(3 / 15)$ & $p=0.46$ & $38 \%(6 / 16)$ & $p=0.79$ \\
\hline Yes & $14 \%(22 / 157)$ & & $35 \%(55 / 159)$ & \\
\hline \multicolumn{5}{|l|}{ Current smoker } \\
\hline No & $14 \%(18 / 127)$ & $p=1.00$ & $30 \%(39 / 129)$ & $p=0.07$ \\
\hline Yes & $14 \%(6 / 44)$ & & $47 \%(21 / 45)$ & \\
\hline \multicolumn{5}{|c|}{ History of drug use (other than marijuana) } \\
\hline No & $14 \%(21 / 146)$ & $p=1.00$ & $35 \%(52 / 149)$ & $p=1.00$ \\
\hline Yes & $14 \%(3 / 21)$ & & $33 \%(7 / 21)$ & \\
\hline \multicolumn{5}{|l|}{ Self-efficacy score } \\
\hline$\geq 5$ (higher self-efficacy) & $12 \%(13 / 107)$ & $p=0.22$ & $28 \%(30 / 108)$ & $p=0.04$ \\
\hline$<5$ (lower self-efficacy) & $22 \%(6 / 27)$ & & $50 \%(14 / 28)$ & \\
\hline \multicolumn{5}{|l|}{ Positive depression screen } \\
\hline No & $13 \%(16 / 124)$ & $p=0.33$ & $31 \%(39 / 125)$ & $p=0.08$ \\
\hline Yes & $20 \%(9 / 46)$ & & $46 \%(22 / 48)$ & \\
\hline \multicolumn{5}{|l|}{ Can you ask doctor for support? } \\
\hline Certain/fairly certain & $14 \%(21 / 155)$ & $p=0.06$ & $33 \%(52 / 156)$ & $p=0.34$ \\
\hline Cannot do & $36 \%(4 / 11)$ & & $50 \%(6 / 12)$ & \\
\hline \multicolumn{5}{|l|}{ Antenatal ART } \\
\hline Zidovudine monotherapy & $29 \%(4 / 14)$ & $p=0.23$ & $64 \%(9 / 14)$ & $p=0.02$ \\
\hline CART & $13 \%(19 / 141)$ & & $31 \%(44 / 143)$ & \\
\hline \multicolumn{5}{|l|}{ Severity of ART side effects } \\
\hline Not bothered or only slightly & $14 \%(18 / 126)$ & $p=0.81$ & $33 \%(42 / 127)$ & $p=0.71$ \\
\hline Somewhat or terribly bothered & $16 \%(7 / 43)$ & & $37 \%(16 / 43)$ & \\
\hline
\end{tabular}


Table 4 Factors associated with poor ART adherence during pregnancy (Continued)

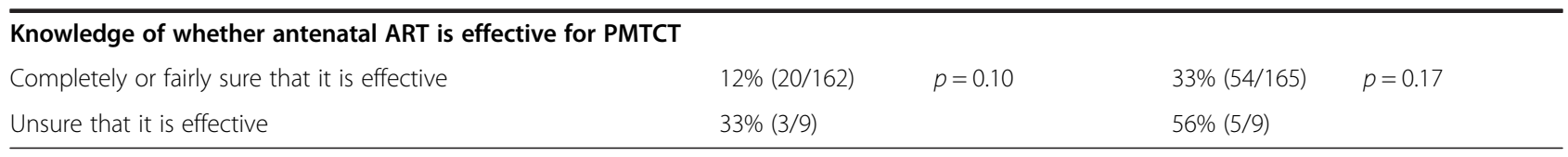

$\mathrm{p}$ values $\leq 0.5$ are indicated in bold.

also more likely to disengage from care after delivery. We therefore could not make meaningful comparisons of adherence between the two time periods. Women receiving antenatal ZDVm reported poorer adherence overall than those receiving cART, possibly because ZDVm is used preferentially among women with indicators of social disadvantage [5], and because women initiating cART may receive more intensive adherence counselling. ZDVm (WHO Option A) is no longer recommended by the WHO for PMTCT [38]; the shift in international guidelines towards lifelong cART for all pregnant HIV-positive women (WHO Option $\mathrm{B}+$ ) [38] underscores the importance of adherence support continuing postpartum for the success of future treatment programmes [39]. Of note, a minority (12/93) of postnatal respondents reported a decline in adherence following delivery but only two reported an improvement. We were therefore not able to rule out poorer levels of adherence postpartum, as has been reported elsewhere [13,14,21-23].

Poor adherence during pregnancy was more commonly reported among women living with their extended family, women not living with a partner, younger women and those with an unplanned pregnancy (factors which were inter-related). Lack of financial support from a partner has been associated with poor ART adherence among women in South Africa [40], and younger age with increased risk of poor ART adherence and/or poor virological outcomes in the UK and North America [41-43], including among pregnant and postpartum women [16,17]. Our findings on the association between poor adherence and lack of disclosure to family members among the sub-group of women living with their extended family highlight the importance of providing support for disclosure within the household. Of note, 1 in 10 women reported being unable to take ART in front of someone who was unaware of their HIV status.

Women with other specific poor health behaviours were more likely to report poor adherence. This included current smokers, who were more likely to report having missed a dose (statistically significant only postnatally), and are a generally less affluent group [44]. There was some evidence of an association between history of drug use and poor ART adherence postnatally but not during pregnancy in our study. IDUs engaged with PMTCT interventions (and particularly those having taken antenatal ART for $\geq 4$ weeks - an inclusion criteria for this study) may be a select group better able to adhere than those receiving ART for their own health postnatally.

Lower ART-related self-efficacy was associated with self-report of $\geq 1$ missed dose during pregnancy and a CASE score $\leq 11$ postnatally. Women with a positive depression screening test were also slightly less likely to report complete antenatal adherence $(p=0.08)$. Cognitivebehavioural interventions to increase self-efficacy have been associated with reduced depressive symptoms, increases in CD4 count and decreases in viral load among HIV-positive women in the US $[45,46]$, and are a potential area for intervention in this population. CASE scores $\leq 11$ were more common antenatally among women not confident to seek information and support from their doctor. The time needed to build a positive, trusting relationship with a healthcare provider, of potential importance to adherence behaviours $[47,48]$, is limited before initiating ART during pregnancy. Pregnant women have specific counselling needs regarding ART preparedness - e.g. the exacerbation of side effects by physical changes during pregnancy [14] - and our results highlight areas for improvement, particularly around the risks and benefits of ART. As the number of HIV-positive pregnant women in Ukraine increases and ART coverage expands [3,5], strategies are needed to ensure sustainable delivery of highquality counselling. Support services were most commonly used in our sample after delivery, suggesting that access could be improved in pregnancy. Women using treatment adherence programmes were more likely to report good adherence postnatally, but further work is needed to assess the impact of these programmes in specific groups.

This study is limited by its use of a self-report adherence measure which, while shown to be associated with virological response [27-29], is likely to over-estimate actual levels of adherence. The sample size of the surveys and the lack of variability in CASE scores limited statistical power to detect differences in ART adherence by maternal characteristics, particularly postpartum, as the proportion of women eligible to continue ART after delivery and their long follow-up intervals and loss to follow-up [24] restricted the number of women eligible and available to participate. The trends in characteristics of participants who reported $\geq 1$ missed dose (the more sensitive of the two outcome measures studied) were broadly similar to those with a CASE score $\leq 11$ points in the antenatal survey, with the exception of smokers and those not living with a 
Table 5 Factors associated with poor ART adherence in the year following delivery

\begin{tabular}{|c|c|c|c|c|}
\hline & $\begin{array}{l}\text { CASE score } \leq 11 \\
\text { points }(8 / 99)\end{array}$ & Fisher's exact test & $\begin{array}{l}\geq 1 \text { missed } \\
\text { dose }(31 / 100)\end{array}$ & Fisher's exact test \\
\hline \multicolumn{5}{|l|}{ Age } \\
\hline$<25$ years & $9 \%(2 / 22)$ & $p=0.95$ & $23 \%(5 / 22)$ & $p=0.37$ \\
\hline $25-27$ years & $7 \%(1 / 15)$ & & $19 \%(3 / 16)$ & \\
\hline $28-30$ years & $5 \%(1 / 21)$ & & $29 \%(6 / 21)$ & \\
\hline$\geq 31$ years & $10 \%(4 / 40)$ & & $40 \%(16 / 40)$ & \\
\hline \multicolumn{5}{|l|}{ Marital status } \\
\hline Married & $6 \%(3 / 54)$ & $p=0.13$ & $22 \%(12 / 55)$ & $p=0.08$ \\
\hline Cohabiting & $19 \%(4 / 21)$ & & $38 \%(8 / 21)$ & \\
\hline Single & $4 \%(1 / 24)$ & & $46 \%(11 / 24)$ & \\
\hline \multicolumn{5}{|l|}{ Lives with family } \\
\hline No & $8 \%(6 / 75)$ & $p=1.00$ & $30 \%(23 / 76)$ & $p=0.80$ \\
\hline Yes & $9 \%(2 / 23)$ & & $35 \%(8 / 23)$ & \\
\hline \multicolumn{5}{|l|}{ Lives with partner } \\
\hline No & $10 \%(2 / 21)$ & $p=0.68$ & $48 \%(10 / 21)$ & $p=0.11$ \\
\hline Yes & $8 \%(6 / 77)$ & & $27 \%(21 / 78)$ & \\
\hline \multicolumn{5}{|l|}{ Disclosed HIV status to anyone } \\
\hline No & $14 \%(1 / 7)$ & $p=0.46$ & $71 \%(5 / 7)$ & $p=0.03$ \\
\hline Yes & $8 \%(7 / 91)$ & & $28 \%(26 / 92)$ & \\
\hline \multicolumn{5}{|l|}{ Current smoker } \\
\hline No & $6 \%(4 / 71)$ & $p=0.20$ & $25 \%(18 / 72)$ & $p=0.03$ \\
\hline Yes & $15 \%(4 / 26)$ & & $50 \%(13 / 26)$ & \\
\hline \multicolumn{5}{|c|}{ History of drug use (other than marijuana) } \\
\hline No & $8 \%(6 / 78)$ & $p=0.63$ & $28 \%(22 / 79)$ & $p=0.08$ \\
\hline Yes & $12 \%(2 / 17)$ & & $53 \%(9 / 17)$ & \\
\hline \multicolumn{5}{|c|}{ Using treatment adherence programme } \\
\hline No & $7 \%(4 / 60)$ & $p=0.71$ & $38 \%(23 / 61)$ & $p=0.08$ \\
\hline Yes & $10 \%(4 / 39)$ & & $21 \%(8 / 39)$ & \\
\hline \multicolumn{5}{|l|}{ Self-efficacy score } \\
\hline$\geq 5$ (higher self-efficacy) & $5 \%(3 / 55)$ & $p=0.05$ & $36 \%(20 / 55)$ & $p=0.32$ \\
\hline$<5$ (lower self-efficacy) & $27 \%(3 / 11)$ & & $55 \%(6 / 11)$ & \\
\hline \multicolumn{5}{|l|}{ Positive depression screen } \\
\hline No & $7 \%(5 / 71)$ & $p=0.68$ & $28 \%(20 / 72)$ & $p=0.46$ \\
\hline Yes & $11 \%(3 / 27)$ & & $37 \%(10 / 27)$ & \\
\hline \multicolumn{5}{|l|}{ Severity of ART side effects } \\
\hline Not bothered or only slightly & $8 \%(6 / 74)$ & $p=1.00$ & $29 \%(22 / 75)$ & $p=0.46$ \\
\hline Somewhat or terribly bothered & $8 \%(2 / 24)$ & & $38 \%(9 / 24)$ & \\
\hline
\end{tabular}

$\mathrm{p}$ values $\leq 0.5$ are indicated in bold.

partner, for whom an increased risk of $\geq 1$ missed dose was detected but not an increased risk of having a CASE score $\leq 11$ points. In the postnatal survey, women not living with a partner were also at increased risk of $\geq 1$ missed dose but not a CASE score $\leq 11$ points, as were women who had not disclosed their HIV status to anyone, single women, those with a history of drug use, and those not using a treatment adherence programme. This partly reflects greater statistical power to detect differences by reporting of $\geq 1$ missed dose compared with CASE score $\leq 11$ (due to the larger number of women reaching the more sensitive cut-off), but possibly also the characteristics of women with early indications of adherence problems. 
Participation rates were estimated at $39-49 \%$ of eligible women in the antenatal survey and around $75 \%$ of eligible women on ART in the postnatal survey. Importantly, some women most at risk of poor adherence may have been excluded due to our eligibility criteria (of note, survey participants were more highly educated than women enrolling only in the ECS) and we may therefore have over-estimated adherence levels in the populations of interest.

Our study design and the use of both WHO Option A and Option B strategies for women requiring ART for PMTCT precluded comparison of adherence during pregnancy and after delivery; future longitudinal studies are needed to assess changes in adherence over time in the subgroup of women who have treatment indications for their own health and continue ART postnatally.

\section{Conclusions}

Our results highlight unmet needs for counselling and support and identify some risk groups - particularly women with markers of social vulnerability, substance users and those with low ART-related self-efficacy who may benefit from targeted interventions to support ART adherence during pregnancy and postnatally.

\section{Abbreviations}

ART: Antiretroviral therapy; CART: Combination antiretroviral therapy; CASE: Case adherence support evaluation; ECS: European Collaborative Study; MTCT: Mother-to-child transmission; PMTCT: Prevention of mother-to-child transmission; WHO: World Health Organisation; ZDVm: Zidovudine monotherapy.

\section{Competing interests}

The authors declare that they have no competing interests.

\section{Authors' contributions}

$\mathrm{HB}$ designed the study, analysed and interpreted the data and drafted the manuscript; CTh designed the study, interpreted the data and revised the manuscript; RM designed the study and revised the manuscript; CTo interpreted the data and revised the manuscript; IS designed the study, acquired the data and revised the manuscript; MCB analysed and interpreted the data and revised the manuscript. All authors have read and approved the final manuscript.

\section{Acknowledgements}

The ECS has approval from the Great Ormond Street Hospital for Children NHS Trust/Institute of Child Health Research Ethics Committee and additional approval for this Adherence Study was obtained from the UCL Research Ethics Committee (3061/001). As there is no formal ethics review process in Ukraine for studies conducted within the public healthcare system, local institutional review board approval was granted by clinic directors on an individual clinic basis at each participating site (Odessa Regional Centre for HIV/AIDS, Kiev City Centre for HIV/AIDS, Donetsk Regional Centre for HIV/AIDS, Kriviy Rig City Centre for HIV/AIDS, Mykolaiv Regional Centre for HIV/AIDS and Simferopol Crimean Republic Centre for HIV/AIDS, Odessa Regional Hospital, Kiev Maternity Hospital and Simferopol Maternity Hospital).

The Ukraine European Collaborative Study Group consists of the following members: T. Pilipenko, A. Zayats, (Perinatal Prevention of AIDS Initiative, Odessa, Ukraine), Dr. S. Posokhova (Regional Hospital, Odessa, Ukraine), Dr. T. Kaleeva, Dr. Y. Barishnikova, Dr. S. Servetsky, Dr. R. Teretsenko (Odessa Regional Centre for HIV/AIDS, Ukraine), Dr. A. Stelmah, Dr. G. Kiseleva, Dr. E. Dotsenko, Dr. O. A. Zalata (Crimean Republic Centre for HIV/AIDS, Ukraine), Dr. S. Solokha, Dr. M. P. Grazhdanov, Dr. E. Kulakovskaya (Donetsk Regional Centre for HIV/AIDS, Ukraine), Dr. N. Bashkatova, Dr. V. Gigil (Mariupol AIDS Center, Ukraine), Dr. I. Raus, Dr. O. V. Yurchenko, Dr. I. Adeyanova (Kiev City
Centre for HIV/AIDS, Ukraine), Dr. Z Ruban, Dr. O Govorun, Dr. O Ostrovskaya, Dr. I Kochergina, (Mikolaiv Regional Centre for HIV/AIDS, Ukraine), Dr. L Kvasha, Dr. G Kruglenko, Dr. N. Primak (Kriviy Rig City Center for HIV/AIDS, Ukraine). The ECS is part of EuroCoord.

REDCap (Research Electronic Data Capture), used for this study, is a secure, web-based application designed to support data capture for research studies, providing: 1) an intuitive interface for validated data entry; 2) audit trails for tracking data manipulation and export procedures; 3) automated export procedures for seamless data downloads to common statistical packages; and 4) procedures for importing data from external sources [34].

Heather Bailey was supported by a Medical Research Council (MRC) Doctoral Training Account PhD Studentship. Claire Townsend was funded by the WellChild Trust through a Research Training Fellowship. Claire Thorne held a Wellcome Trust Research Career Development Fellowship 2007-2012, which provided support for the adherence surveys (grant number 081082) and the nested postnatal survey. The ECS receives funding from the EU Seventh Framework Programme (FP7/2007-2013) under EuroCoord grant agreement $n^{\circ}$ 260694. Some of this work was undertaken at GOSH/UCL Institute of Child Health which received a proportion of funding from the UK Department of Health's NIHR Biomedical Research Centres funding scheme. Funders were not involved in the study design, execution or analysis or the decision to submit the manuscript for publication, and the authors maintain full control of all primary data.

These findings were previously presented at the 7th International AIDS Society Conference on HIV Pathogenesis, Treatment and Prevention, 30 June - 3 July 2013, Kuala Lumpur, Malaysia (Abstract TUPE295).

\section{Author details}

${ }^{1}$ Population Policy and Practice Programme, UCL Institute of Child Health, University College London, 30 Guilford Street, London WC1N 1EH, UK.

${ }^{2}$ Perinatal Prevention of AIDS Initiative, Odessa, Ukraine.

Received: 27 February 2014 Accepted: 18 September 2014

Published: 24 September 2014

\section{References}

1. WHO, UNAIDS, UNICEF: Global HIV/AIDS Response. Epidemic Update and Health Sector Progress towards Universal Access. Progress Report 2011. 2011.

2. UNAIDS: UNAIDS report on the global AIDS epidemic 2013. 2013. Available at http://www.unaids.org/en/media/unaids/contentassets/ documents/epidemiology/2013/gr2013/UNAIDS_Global_Report_2013_en. pdf (accessed September 2014).

3. Ministry of Health of Ukraine: Ukraine Harmonized AIDS Response Progress Report. Reporting Period: January 2010 - December 2011. Kiev, Ukraine: Ministry of Health of Ukraine; 2012.

4. WHO: Antiretroviral Drugs for Treating Pregnant Women and Preventing HIV Infection in Their Infants: Recommendations for a Public Health Approach. 2010 Version. Geneva, Switzerland: World Health Organization; 2010.

5. Bailey H, Townsend CL, Semenenko I, Malyuta R, Cortina-Borja M, Thorne C, Ukraine European Collaborative Study Group in E: Impact of expanded access to combination antiretroviral therapy in pregnancy: results from a cohort study in Ukraine. Bull World Health Organ 2013, 91(7):491-500.

6. Ministry of Health of Ukraine: Ukraine: National Report on Monitoring Progress Towards the UNGASS Declaration of Commitment on HIV/AIDS, January 2008-December 2009. Kiev: Ministry of Health of Ukraine; 2010.

7. Gross R, Yip B, Lo Re V III, Wood E, Alexander CS, Harrigan PR, Bangsberg DR, Montaner JSG, Hogg RS: A simple dynamic measure of antiretroviral therapy adherence predicts failure to maintain HIV-1 suppression. $J$ Infect Dis 2006, 194:1108-1114.

8. Lima VD, Harrigan R, Murray M, Moore DM, Wood E, Hogg RS, Montaner JSG: Differential impact of adherence on long-term treatment response among naive HIV-infected individuals. AIDS 2008, 22:2371-2380.

9. Lima VD, Harrigan R, Bangsberg DR, Hogg RS, Gross R, Yip B, Montaner JSG: The combined effect of modern highly active antiretroviral therapy regimens and adherence on mortality over time. J Acquir Immune Defic Syndr 2009, 50(5):529-536.

10. Warszawski J, Tubiana R, Le Chenadec J, Blanche S, Teglas JP, Dollfus C, Faye A, Burgard M, Rouzioux C, Mandelbrot L, ANRS French Perinatal Cohort: Mother-to-child HIV transmission despite antiretroviral therapy in the ANRS french perinatal cohort. AIDS 2008, 22(2):289-299. 
11. Townsend CL, Cortina-Borja M, Peckham CS, de Ruiter A, Lyall H, Tookey PA: Low rates of mother-to-child transmission of HIV following effective pregnancy interventions in the United Kingdom and Ireland, 2000-2006. AIDS 2008, 22(8):973-981.

12. Desai N, Mathur M: Selective transmission of multidrug resistant HIV to a newborn related to poor maternal adherence. Sex Transm Infect 2003, 79:419-421

13. Mellins CA, Chu C, Malee K, Allison S, Smith R, Harris L, Higgins A, Zorrilla C, Landesman S, Serchuck L, Larussa P: Adherence to antiretroviral treatment among pregnant and postpartum HIV-infected women. AIDS Care 2008, 20(8):958-968

14. Cohn SE, Umbleja T, Mrus J, Bardeguez AD, Andersen JW, Chesney MA: Prior illicit drug use and missed prenatal vitamins predict nonadherence to antiretroviral therapy in pregnancy: adherence analysis A5084. AIDS Patient Care STDS 2008, 22(1):29-40.

15. Kingston MA, Letham CJ, McQuillan O: Adherence to antiretroviral therapy in pregnancy. Int J STD AIDS 2007, 18(11):787-789.

16. Turner BJ, Newschaffer CJ, Zhang D, Cosler L, Hauck WW: Antiretroviral Use and pharmacy-based measurement of adherence in postpartum HIV-infected women. Med Care 2000, 38(9):911-925.

17. Laine C, Newschaffer CJ, Zhang D, Cosler L, Hauck WW, Turner BJ: Adherence to antiretroviral therapy by pregnant women infected with human immunodeficiency virus: a pharmacy claims-based analysis. Obstet Gynecol 2000, 95(2):167-173.

18. Minozzi S, Amato L, Vecchi S, Davoli M: Maintenance agonist treatments for opiate dependent pregnant women. Cochrane Database Syst Rev 2008, 16(2):CD006318

19. Judice N, Zaglada O, Mbuya-Brown R: HIV Policy Assessment: Ukraine. In Washington, DC: Futures Group, Health Policy Project; 2011.

20. Nachega JB, Uthman OA, Anderson J, Peltzer K, Wampold S, Cotton MF, Mills EJ, Ho YS, Stringer JS, Mclntyre JA, Mofenson LM: Adherence to antiretroviral therapy during and after pregnancy in low-income, middle-income, and high-income countries: a systematic review and meta-analysis. AIDS 2012, 26(16):2039-2052.

21. Vaz MJ, Barros SM, Palacios R, Senise JF, Lunardi L, Amed AM, Castelo A: HIV-infected pregnant women have greater adherence with antiretroviral drugs than non-pregnant women. Int J STD AIDS 2007, 18:28-32.

22. Bardeguez AD, Lindsey JC, Shannon M, Tuomala RE, Cohn SE, Smith E, Stek A, Buschur S, Cotter A, Bettica L, Read JS: Adherence to antiretrovirals among US women during and after pregnancy. J Acquir Immune Defic Syndr 2008, 48(4):408-417.

23. Ickovics JR, Wilson TE, Royce RA, Minkoff HL, Fernandez MI, Fox-Tierney R, Koenig LJ: Prenatal and postpartum zidovudine adherence among pregnant women with HIV: results of a MEMS substudy from the Perinatal Guidelines Evaluation Project. J Acquir Immune Defic Syndr 2002, 30(3):311-315

24. Bailey H, Thorne C, Semenenko I, Malyuta R, Tereschenko R, Adeyanova I, Kulakovskaya E, Ostrovskaya L, Kvasha L, Cortina-Borja M, Townsend CL: Cervical screening within HIV care: findings from an HIV-positive cohort in Ukraine. PLoS One 2012, 7(4):e34706.

25. AIDS Clinical Trials Group: Center for AIDS prevention studies (CAPS) instruments: ACTG adherence baseline questionnaire. 2010. Accessed September 2012. http://caps.ucsf.edu/uploads/tools/surveys/pdf/ 2098.4186.pdf.

26. NIAID Adult AIDS Clinical Trials Group: Supplemental antepartum adherence questionnaire. 2001. Accessed August 2014. Available at https:// www.fstrf.org/apps/cfmx/apps/common/QOLAdherenceForms/index.cfm? project=ACTG

27. Mannheimer SB, Mukherjee R, Hirschhorn LR, Dougherty J, Celano SA, Ciccarone D, Graham KK, Mantell JE, Mundy LM, Eldred L, Botsko M, Finkelstein R: The CASE adherence index: a novel method for measuring adherence to antiretroviral therapy. AIDS Care 2006, 18(7):853-861.

28. Kerr SJ, Avihingsanon A, Putcharoen O, Chetchotisakd P, Layton M, Ubolyam S, Ruxrungtham K, Cooper DA, Phanuphak P, Duncombe C: Assessing adherence in Thai patients taking combination antiretroviral therapy. Int J STD AIDS 2012, 23(3):160-165.

29. Apisarnthanarak A, Mundy LM: Application of a 3-item adherence metric to monitor antiretroviral medication adherence in a resource-limited setting. J Acquir Immune Defic Syndr 2010, 55(4):528.

30. Simoni JM, Kurth AE, Pearson CR, Pantalone DW, Merrill JO, Frick PA: Self-report measures of antiretroviral therapy adherence: a review with recommendations for HIV research and clinical management. AIDS Behav 2006, 10:227-245

31. Whooley MA, Avins AL, Miranda J, Browner WS: Case-finding instruments for depression: two questions are as good as many. J Gen Intern Med 1997, 12:439-445.

32. Arroll B, Goodyear-Smith F, Kerse N, Fishman T, Gunn J: Effect of the addition of a "help" question to two screening questions on specificity for diagnosis of depression in general practice: diagnostic validity study. BMJ 2005, 331(7521):884.

33. AIDS Clinical Trials Group: Center for AIDS Prevention Studies (CAPS) instruments: the HIV treatment adherence self-efficacy scale. 2010. Accessed September 2012. http://caps.ucsf.edu/uploads/tools/surveys/pdf/ HIV-ASES.pdf.

34. Harris PA, Taylor R, Thielke R, Payne J, Gonzalez N, Conde JG: Research electronic data capture (REDCap)-A metadata-driven methodology and workflow process for providing translational research informatics support. J Biomed Inform 2009, 42(2):377-381.

35. Bangsberg DR, Hecht FM, Charlebois ED, Zolopa A, Holodniy M, Sheiner L, Bamberger JD, Chesney MA, Moss A: Adherence to protease inhibitors, HIV-1 viral load, and development of drug resistance in an indigent population. AIDS 2000, 14:357-366

36. Liu H, Golin CE, Miller LG, Hays RD, Beck CK, Sanandaji S, Christian JMT, Duran D, Kaplan AH, Wenger NS: A comparison study of multiple measures of adherence to HIV protease inhibitors. Ann Intern Med 2001, 134:968-977.

37. Kimmerling M, Wagner G, Ghosh-Dastidar B: Factors associated with accurate self-reported adherence to HIV antiretrovirals. Int J STD AIDS 2003, 14:281-284.

38. WHO: Consolidated Guidelines on the use of Antiretroviral Drugs for Treating and Preventing HIV Infection. Geneva, Switzerland: World Health Organisation; 2013

39. Ahmed S, Kim MH, Abrams EJ: Risks and benefits of lifelong antiretroviral treatment for pregnant and breastfeeding women: a review of the evidence for the Option B + approach. Curr Opin HIN AIDS 2013, 8(5):474-489.

40. El-Khatib Z, Ekstrom AM, Coovadia A, Abrams EJ, Petzold M, Katzenstein D, Morris $L$, Kuhn $L$ : Adherence and virologic suppression during the first 24 weeks on antiretroviral therapy among women in Johannesburg, South Africa - a prospective cohort study. BMC Public Health 2011, 11:88.

41. Sherr L, Lampe FC, Clucas C, Johnson M, Fisher M, Leake Date H, Anderson J, Edwards S, Smith CJ, Hill T, Harding R: Self-reported non-adherence to ART and virological outcome in a multiclinic UK study. AIDS Care 2010, 22(8):939-945.

42. Sabin CA, Smith CJ, d'Arminio Monforte A, Battegay M, Gabiano C, Galli L, Geelen S, Gibb D, Guiguet M, Judd A, Leport C, Dabis F, Pantazis N, Porter K, Raffi F, Thorne C, Torti C, Walker S, Warszawski J, Wintergerst U, Chene G, Lundgren J: Response to combination antiretroviral therapy: variation by age. AIDS 2008, 22(12):1463-1473.

43. Hadland SE, Milloy MJ, Kerr T, Zhang R, Guillemi S, Hogg RS, Montaner JS, Wood E: Young age predicts poor antiretroviral adherence and viral load suppression among injection drug users. AIDS Patient Care STDS 2012, 26(5):274-280.

44. Palipudi KM, Gupta PC, Sinha DN, Andes LJ, Asma S, McAfee T, Group GC: Social determinants of health and tobacco use in thirteen low and middle income countries: evidence from Global Adult Tobacco Survey. PLoS One 2012, 7(3):e33466

45. Ironson G, Weiss S, Lydston D, Ishii M, Jones D, Asthana D, Tobin J, Lechner S, Laperriere A, Schneiderman N, Antoni M: The impact of improved selfefficacy on HIV viral load and distress in culturally diverse women living with AIDS: the SMART/EST Women's Project. AIDS Care 2005, 17(2):222-236.

46. Jones DL, Ishii Owens M, Lydston D, Tobin JN, Brondolo E, Weiss SM: Self-efficacy and distress in women with AIDS: the SMART/EST women's project. AIDS Care 2010, 22(12):1499-1508.

47. Johnston Roberts K, Volberding P: Adherence communication: a qualitative analysis of physician-patient dialogue. AIDS 1999, 13:1771-1778.

48. Golin CE, Liu H, Hays RD, Miller LG, Beck CK, Ickovics J, Kaplan AH, Wenger NS: A prospective study of predictors of adherence to combination antiretroviral medication. J Gen Intern Med 2002, 17:756-765.

doi:10.1186/1471-2458-14-993

Cite this article as: Bailey et al:: Adherence to antiretroviral therapy during pregnancy and the first year postpartum among HIV-positive women in Ukraine. BMC Public Health 2014 14:993. 